\begin{tabular}{|c|c|c|c|c|c|}
\hline MUNIBE Antropologia-Arkeologia & $n^{0} 72$ & $43-56$ & DONOSTIA & 2021 & ISSN 1132-2217 • eISSN 2172-4555 \\
\hline
\end{tabular}

\title{
Los objetos elaborados con fibras vegetales del Neolítico Antiguo de Coves del Fem, Ulldemolins (Tarragona)
}

\author{
The fibre-based objects from the Early Neolithic \\ site of Coves del Fem, Ulldemolins (Tarragona)
}

PALABRAS CLAVES: Fibras vegetales, cestería cosida, cordelería, Neolítico Antiguo. GAKO-HITZAK: Zuntz begetalak, jositako saskigintza, sokagintza, Antzinako Neolitoa. KEY WORDS: Vegetal fibres, coiled basketry, cordage, early Neolithic.

\author{
Susagna ROMERO-BRUGUÉS(1)*, Maria HERRERO-OTAL(1), Raquel PIQUÉ(1), Rafel ROSILLO(2) \\ Xavier TERRADAS ${ }^{(3)}$, Oriol LÓPEZ-BULTÓ(1), Anna BERROCAL-BARBERÀ(1), Antoni PALOMO ${ }^{(4)}$
}

\section{RESUMEN}

Los objetos manufacturados con materias orgánicas raramente se conservan excepto bajo condiciones ambientales específicas, ya sea en medios de sequedad constante, en contextos anaeróbicos sumergidos, bajo congelación o por carbonización. Por ello, las técnicas de cestería y cordelería, así como las materias primas utilizadas están escasamente documentadas en el registro arqueológico del Neolítico peninsular. Se aporta aquí nueva información acerca de las técnicas cesteras y de cordelería, así como de las materias primas utilizadas en Coves del Fem (Ulldemolins, Tarragona). Estos restos fueron recuperados en una fosa adscribible al Neolítico antiguo. La cestería estudiada se encuentra manufacturada a través de la técnica de espiral cosida, mientras que en el caso de la cordelería se trata de un único fragmento torsionado. Se discute su funcionalidad en un contexto de hábitat en cueva, así como su tecnología y materias primas usadas, contextualizándolos con otros ejemplos de cestería de espiral cosida de la península ibérica.

\section{LABURPENA}

Materia organikoekin egindako objektuek ingurumen-baldintza espezifikoetan bakarrik irauten dute: lehortasun iraunkorretan, murgildutako testuinguru anaerobikoetan, izoztuta edo ikaztuta, adibidez. Horregatik, gutxi dira penintsulako Neolitoko erregistro arkeologikoan dokumentatutako erabilitako lehengaiak eta saskigintzako eta sokagintzako teknikak. Saskigintzako eta sokagintzako teknikei buruzko informazio berria gehitu dugu hemen. Gainera, Coves del Fem-en (Ulldemolins, Tarragona) erabilitako lehengaiei buruzko informazioa ere eskaini dugu. Antzinako Neolitoan koka dezakegun hobi batean berreskuratu zituzten aztarna horiek. Aztertutako saskigintza jositako espiralaren teknika bidez fabrikatuta dago; aldiz, sokagintzaren kasuan, bihurtutako pusketa bakarra da. Iberiar penintsulako jositako espiraleko saskigintzako beste adibide batzuekin alderatuta, erabilitako lehengaien eta teknologiaren funtzionalitatea jorratu ditugu kobazuloko habitataren testuingurua kontuan hartuta.

\section{ABSTRACT}

Plant-based artefacts are considered one of the first technologies used by human populations playing an important role in the daily life of all societies. Even though, they are made of perishable material which usually disappears in archaeological contexts except for some specific environmental conditions that permit their conservation as arid, anaerobic, waterlogged atmospheres or carbonization. Some examples of the first implements produced by organic materials are baskets and cords which are documented since the very beginning of human populations. Nevertheless, these fibre-based materials have been excluded from archaeological studies. The lack of knowledge in this vegetal technology is a consequence of the difficulty of organic material preservation and the non-suitable analysis and identification methodologies. Even they represent a living material culture as history and ethnography demonstrate, vegetal fibres were probably used for producing indispensable everyday objects and artefacts in the past. The aim of this paper is to provide new information about vegetal technology as basketry and cordage techniques, as well as the raw materials used in Neolithic chronologies in the North-East of the Iberian Peninsula.

The materials analyzed in this study were recovered at the site of Coves del Fem (Ulldemolins, Tarragona) which is a rock shelter preserved thanks to the fallen rock blocks. Basketry and cordage fragments came from the archaeological fieldwork of 2019 and were recovered inside a pit in levels of the final Early Neolithic. They were preserved thanks to the carbonization and dehydration they were submitted to. Both basketry and cordage examples from Coves del Fem, were deeply described considering their morphology and technology, as well as the raw materials they were made of. The methodology consisted of describing the technique used and taking measures of the different fragments aiming to obtain information about the way the basket and the cord were made. The identification of raw materials was performed by observing cross, peridermal and longitudinal sections of samples using a transmitted optical microscope. Descriptions were based on microanatomical observation by comparing with reference modern material and specialized technical literature.

\footnotetext{
(1) Departament de Prehistòria, Universitat Autònoma de Barcelona (UAB), Campus Universitario, 08193 Bellaterra. (2) Arqueólogo independiente.

(3) Consejo Superior de Investigaciones Científicas (IMF, Barcelona), Carrer de les Egipcíaques, 15, 08001 Barcelona.

(4) Museu d'Arqueologia de Catalunya, Passeig de Santa Madrona, 39, 08038 Barcelona.

* Correo electrónico de correspondencia del primer autor: sr.brugues@gmail.com.
} 
The results showed the basketry assemblage was produced using the coiling technique and all the fragments belong to a single object. In the case of the cordage fragment, it was made by twisting the fibres which had been previously mechanically processed. The identification of raw materials revealed at least the use of sedges for basketry and non-identified herbaceous plants for making cordage. The functionality of the objects is discussed, and they are also contextualized with other Neolithic fibre productions examples from the Iberian Peninsula and the Middle East, both technologically and the chosen raw materials. In summary, fibre-based productions from Coves del Fem, along with the assemblage from the lake dwelling site of La Draga, fill the gap of this archaeological record from the Iberian Peninsula to Europe, demonstrating the long history of the technical skills related to plant exploitation.

\section{INTRODUCCIÓN}

Los restos de cestería y cordelería, en tanto que objetos manufacturados con materias orgánicas, son poco frecuentes en el registro arqueológico y su conservación se materializa en condiciones muy excepcionales. Por ello, nuestro conocimiento sobre las producciones elaboradas con fibras vegetales es parcial, sesgada y restringida a ciertas áreas geográficas y periodos. Estas circunstancias limitan nuestro conocimiento sobre la llamado cultura material perecedera y de su importancia para las sociedades prehistóricas. Sin embargo, se ha apuntado que probablemente su presencia fue mayoritaria (Hurcombe 2014) y su importancia mucho mayor de lo que permiten suponer los escasos restos recuperados. La proximidad y abundancia de material vegetal, así como la facilidad de su manejo, hacen de la cestería una tecnología sencilla en cuanto a adquisición de la materia prima, su manejo y su posterior transformación en objetos funcionales, al no requerir de abundantes herramientas para el procesado vegetal, siendo muchas veces posible con las propias manos. Este hecho nos permite pensar que su uso fue habitual para las sociedades agrícolas, pero también para las sociedades cazadoras-recolectoras.

La cestería en espiral cosida ha estado presente en sociedades pasadas y su uso ha permitido solucionar diversas necesidades cotidianas, tales como el transporte, almacenamiento o conservación de alimentos.

En Europa, y más concretamente en la península ibérica, se conocen ejemplos cesteros desde finales del Paleolítico Superior a través del conocimiento indirecto, procurado por improntas arcillosas de cestería. Este es el caso de la Cova de Santa Maira (Castell de Castells, Alacant), donde se encontraron restos de improntas arcillosas de cestería tejida y fibras de esparto trenzadas con una cronología entre 12900 - 10200 cal BC (Aura-Tortosa et al., 2019). Estos restos permiten revelar que las técnicas cesteras eran conocidas en la península ibérica mucho antes de la llegada de las primeras comunidades agrícolas y ganaderas, si bien en este caso no se documenta la técnica de cestería en espiral cosida.

Ya de cronología neolítica también contamos con datos indirectos como son las improntas que se conservan en la arcilla de la fosa número 13 de la Cova de les Cendres (Moraira, Alacant) (Bernabeu-Aubán y Fumanal-García, 2009) o las marcas de una estera del yacimiento de la Cova 120 (Sales de Llierca, Girona) (Agustí et al., 1987).
Para el conocimiento de evidencias directas cesteras en Europa nos hemos de remontar al neolítico. A modo de ejemplo, podemos citar los hallazgos de algunos yacimientos lacustres, como los fragmentos de cestería recuperados en los yacimientos de la Marmotta en el lago Bracciano (Italia), datado entre el 5960 - 5260 BC (Fugazzola, 1998), La Draga (Banyoles, España), datados entre 5300 - 5000 cal BC (Romero-Brugués et al., 2021), o las ocupaciones neolíticas datadas entre 4000 - 2400 BC en el entorno del Lago Constanza, como por ejemplo Arbon-Bleiche 3 (Suiza) (Médard, 2003) o Wangen, Allensbach y Sipplingen (Körber-Grohne y Feldtkeller, 1998), Honstaad Hörnle I A (Alemania) (Maier, 1999).

En la península ibérica, son pocos los ejemplos directos recuperados de cestería, además del citado yacimiento de La Draga. Entre estos, cabe destacar el yacimiento funerario de Cueva de los Murciélagos de Albuñol (Granada), donde se recuperaron varios objetos elaborados con fibras vegetales que incluían algunos ejemplos de cestería de esparto (Stipa tenacissima) datados entre 5200 - 4600 cal. BC (Cacho et al., 1996), conservados gracias a las condiciones excepcionales de sequedad constante.

Dados los escasos restos de cestería neolítica conocidos en la península ibérica, no es posible por ahora abordar su origen y desarrollo. Sin embargo, los hallazgos de cestería en espiral cosida realizados en los niveles epicardiales (4941 - 4545 cal BC) (Palomo et al., 2018) de Coves del Fem (Ulldemolins, Tarragona), constituyen un valioso material para conocer las tecnologías aplicadas en la manipulación de plantas y fibras vegetales. Se presentan aquí los resultados del análisis morfotécnico de los restos cesteros y de cordería de Coves del Fem, la identificación de las plantas utilizadas en el proceso de creación de los objetos vegetales y se discute la funcionalidad tanto de la cestería, como de la cordelería recuperados. Con este trabajo se pretende ampliar el conocimiento de las técnicas de cestería cosida empleadas en las primeras etapas del neolítico en la península ibérica. Así mismo, se pretende aportar nuevos datos a partir de la técnica cestera de espiral cosida, y ampliar el conocimiento de la funcionalidad de los objetos cesteros entre las primeras comunidades campesinas, así como aportar nuevos datos sobre la explotación de los recursos vegetales para cestería.

\section{EL YACIMIENTO DE COVES DEL FEM}

El yacimiento de Coves del Fem se localiza en el término municipal de Ulldemolins (Priorat, Tarragona). 
Se trata de un amplio abrigo rocoso situado en el margen izquierdo del río Montsant, a poco más de 10 metros por encima del mismo (Figura 1). La cavidad se ha formado por la acción erosiva del río sobre los conglomerados. Fue descubierto de forma casual en 1997 y se ha excavado de forma intermitente desde el 2013. Las excavaciones realizadas han permitido documentar una amplia estratigrafía que abarca ocupaciones atribuidas al Mesolítico (6065 - 5718 cal BC), la primera fase del Neolítico Antiguo Cardial (5667 - 5476 cal BC) y la última fase del Neolítico antiguo o Epicardial (4941 - 4545 cal BC) (Bogdanovic et al., 2017; Palomo et al., 2018) (Figura 2). La secuencia está formada por una sucesión de arenas, acumuladas como consecuencia de desbordes e inundaciones del río Montsant, en combinación con otros con sedimento de aportación eólica.

Tanto los estudios palinológicos como los antracológicos de los niveles epicardiales han permitido documentar un paisaje dominado por pinares de pino silvestre (Pinus sylvestris-nigra), bosques de robles y encinas (Quercus sp.), tilos (Tilia sp.) y avellanos (Corylus sp.), con presencia de varias plantas herbáceas (Poaceae, Asteraceae y Cyperaceae) y de otras especies de ribera características del río Montsant, como sauces (Salix sp.), olmos (Ulmus sp.), alisos (Alnus sp.) o fresnos (Fraxinus sp.) (Alcolea et al., 2019, Piqué et al., 2021). Los restos carpológicos por su parte determinan el aprovechamiento de los recursos silvestres del entorno, entre ellos bello- tas (Quercus sp.), piñas (Pinus sp.), uvas silvestres (Vitis vinifera var. sylvestris), así como el cultivo de cereales (Palomo et al., 2018). Los restos faunísticos, indican la importancia de la caza durante las ocupaciones neolíticas, así como la presencia de ovicápridos domésticos.

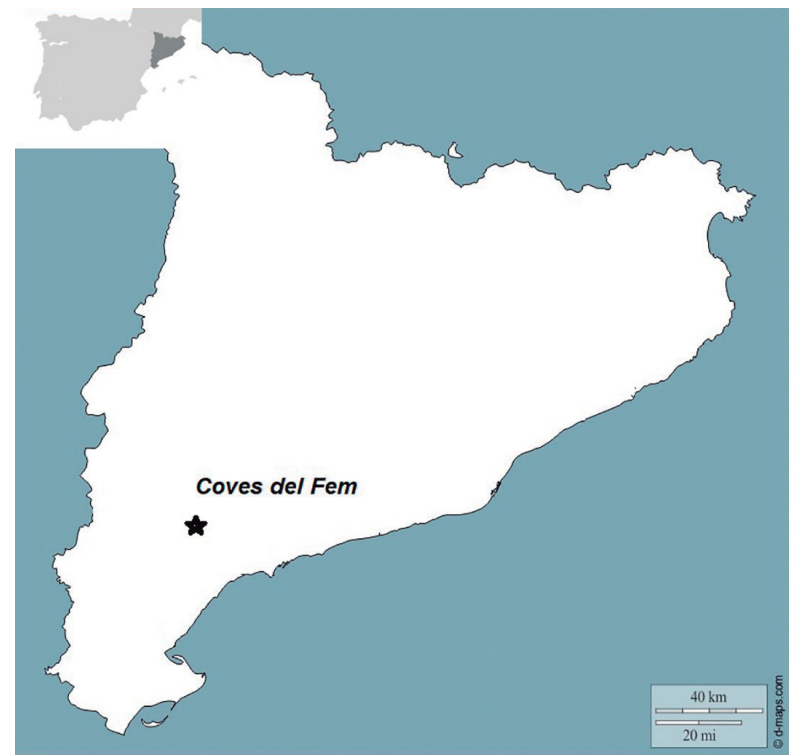

Fig.1. Localización del yacimiento de Coves del Fem. / Location of the site of Coves del Fem.
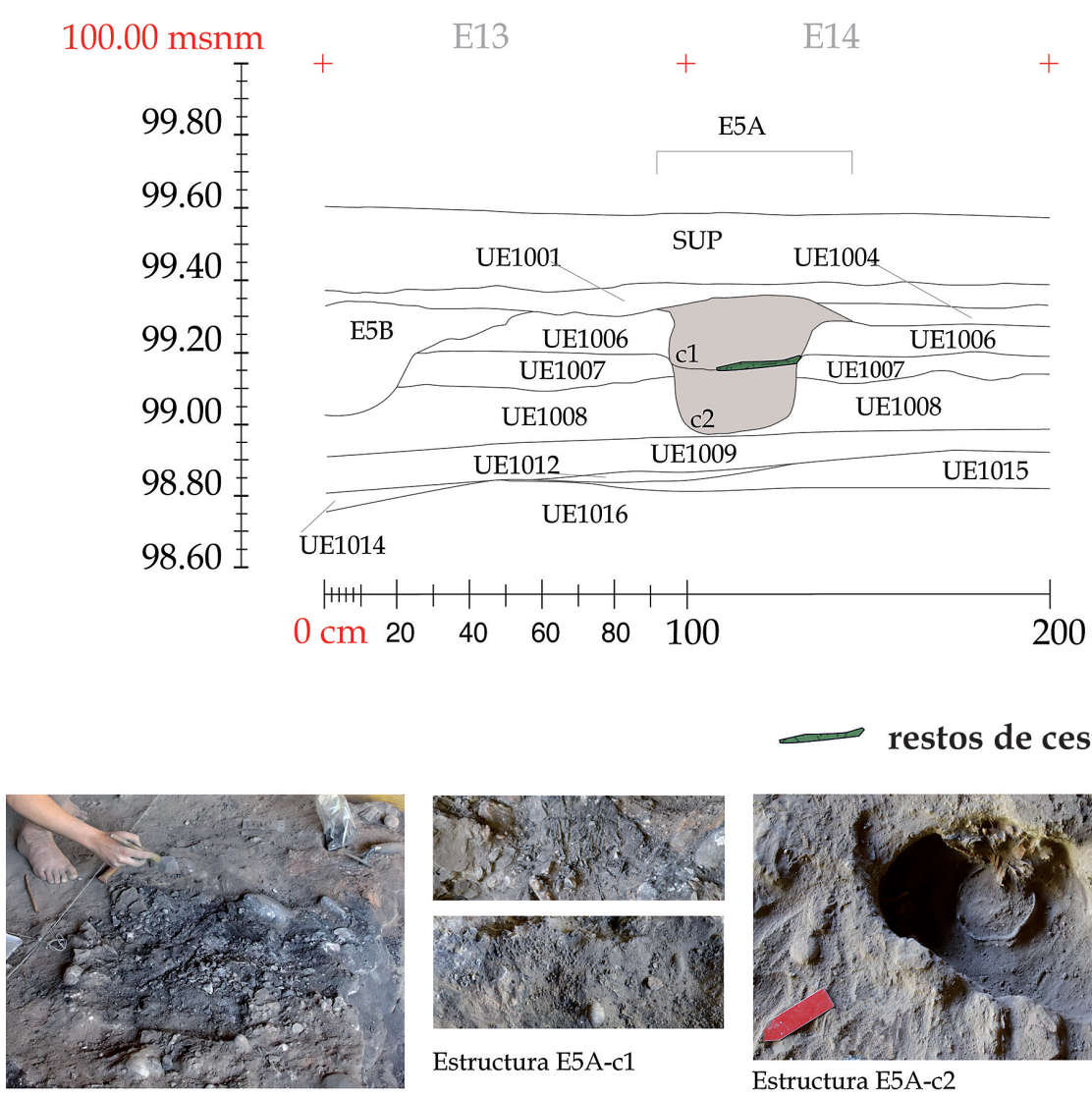

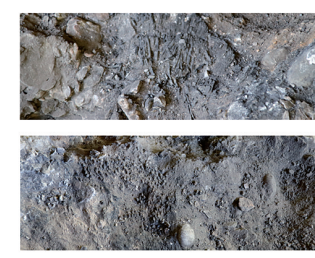

Estructura E5A-c1

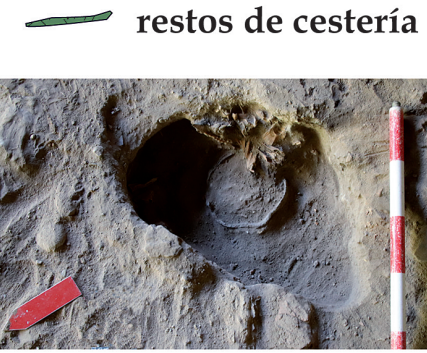

Estructura E5A-c2
Fig.2. Secuencia estratigráfica del yacimiento de Coves del Fem y contexto de localización de los fragmentos de cestería y cordelería. / Stratigraphic sequence of Coves del Fem site and location context of basketry and cordage fragments. 


\subsection{El contexto arqueológico de los restos de cestería}

Los restos de cestería se localizaron en una subestructura ubicada en el interior de la gran estructura E5, sellada por la Unidad Estratigráfica (UE) 1001 (Figura 2). Esta estructura ha sido parcialmente excavada y documentada, debido a que su límite oriental se adentra en el perfil de la zona no excavada y su límite septentrional se halla destruido debido a la acción de excavaciones clandestinas. A pesar de estas circunstancias, las características generales de la E5 permiten interpretarla como un área doméstica bien definida y coherente con las características de una estructura de hábitat. Presenta una acumulación de guijarros y conglomerado fragmentado procedente de la propia roca del abrigo que define un suelo preparado -a modo de encachado- de unos cinco metros cuadrados, una estructura de sostenimiento y dos subestructuras en fosa tipo cubeta. De estas dos fosas, la estructura E5A es la que ha proporcionado los restos de cestería que aquí presentamos.

La subestructura E5A presenta en su parte superior una planta ovalada de sección irregular, y base convexa con una potencia máxima de $40 \mathrm{~cm}$. Su relleno presenta dos capas, la superior tiene $20 \mathrm{~cm}$ de potencia y en ella se ha hallado un elemento macrolítico con restos de ocre, así como un fragmento de ocre de $4 \mathrm{~cm}$. Otros materiales recuperados en esta capa son diversos fragmentos de cerámica muy termoalterados que formarían parte de un mismo recipiente. Es en la base de esta capa dónde aparecen fibras vegetales carbonizadas que formarían parte de los restos de cestería que analizamos en este artículo. La capa inferior está compuesta por arenas finas y poco compactas. Del material arqueológico recuperado en su interior, además de restos líticos abundantes, ha aparecido una importante concentración de semillas carbonizadas, también destacan los restos de un fragmento cerámico. Por debajo de este elemento y en el límite oriental de la estructura, se encuentra un cráneo de cerdo completo apoyado en la pared de la fosa. Entre estos restos faunísticos y la base de la estructura, en su parte central, se extrajo un perfil completo de un recipiente cerámico. Finalmente, y en contacto con la base de la fosa se hallaron restos de material vegetal carbonizado entre el que se apreciaba la presencia de tallos.

\begin{tabular}{|c|c|c|c|c|c|c|c|}
\hline Reg. & $\mathrm{N}^{\circ}$ inventario & Tipo de resto & Tipo elemento analizado & Tipo especie & Nombre científico & Parte anatómica & $\begin{array}{l}\text { Ancho. mínimo } \\
\text { haz }(\mathrm{mm})\end{array}$ \\
\hline \multirow{2}{*}{1} & \multirow{2}{*}{$\begin{array}{c}\text { CDF2019 } \\
261\end{array}$} & \multirow{2}{*}{ HAZ } & cosido & Monoc. (herbácea) & Cyperaceae & No det. & \multirow{2}{*}{17} \\
\hline & & & haz & Monoc. (herbácea) & No det. & No det. & \\
\hline \multirow{2}{*}{2} & \multirow{2}{*}{$\begin{array}{c}\text { CDF2019 } \\
261\end{array}$} & \multirow{2}{*}{$\begin{array}{c}\text { RESTO } \\
\text { INFORME }\end{array}$} & cosido & Monoc. (herbácea) & Cyperaceae & No det. & \multirow{2}{*}{ No det. } \\
\hline & & & haz & Monoc. (herbácea) & No det. & No det. & \\
\hline \multirow{2}{*}{3} & \multirow{2}{*}{$\begin{array}{l}\text { CDF2019 } \\
261\end{array}$} & \multirow{2}{*}{$\begin{array}{l}\text { PUNTADA } \\
\text { COSIDO }\end{array}$} & cosido & Monoc. (herbácea) & Cyperaceae & hoja & \multirow{2}{*}{ No det. } \\
\hline & & & haz & Monoc. (herbácea) & No det. & No det. & \\
\hline \multirow{2}{*}{4} & \multirow{2}{*}{$\begin{array}{c}\text { CDF2019 } \\
261\end{array}$} & \multirow{2}{*}{$\begin{array}{l}\text { PUNTADA } \\
\text { COSIDO }\end{array}$} & cosido & Monoc. (herbácea) & Cyperaceae & hoja & \multirow{2}{*}{ No det. } \\
\hline & & & haz & Monoc. (herbácea) & No det. & No det. & \\
\hline \multirow{2}{*}{5} & \multirow{2}{*}{$\begin{array}{c}\text { CDF2019 } \\
261\end{array}$} & \multirow{2}{*}{$\begin{array}{l}\text { PUNTADA } \\
\text { COSIDO }\end{array}$} & cosido & Monoc. (herbácea) & Cyperaceae & hoja & \multirow{2}{*}{ No det. } \\
\hline & & & haz & Monoc. (herbácea) & No det. & No det. & \\
\hline \multirow{2}{*}{6} & \multirow{2}{*}{$\begin{array}{c}\text { CDF2019 } \\
261\end{array}$} & \multirow{2}{*}{$\mathrm{HAZ}$} & cosido & Monoc. (herbácea) & Cyperaceae & No det. & \multirow{2}{*}{3} \\
\hline & & & haz & Monoc. (herbácea) & No det. & No det. & \\
\hline \multirow{2}{*}{7} & \multirow{2}{*}{$\begin{array}{c}\text { CDF2019 } \\
261\end{array}$} & \multirow{2}{*}{$\mathrm{HAZ}$} & cosido & Monoc. (herbácea) & Cyperaceae & No det. & \multirow{2}{*}{6} \\
\hline & & & haz & Monoc. (herbácea) & No det. & No det. & \\
\hline \multirow{2}{*}{8} & \multirow{2}{*}{$\begin{array}{l}\text { CDF2019 } \\
261\end{array}$} & \multirow{2}{*}{$\mathrm{HAZ}$} & cosido & Monoc. (herbácea) & Cyperaceae & No det. & \multirow{2}{*}{-} \\
\hline & & & haz & Monoc. (herbácea) & No det. & No det. & \\
\hline 9 & CDF2019 & HAZ & cosido & Monoc. (herbácea) & Cyperaceae & hoja & 9 \\
\hline$y$ & 261 & MAL & haz & Monoc. (herbácea) & No det. & No det. & $y$ \\
\hline 10 & CDF2019 & BASE O & cosido & Monoc. (herbácea) & Cyperaceae & hoja & \\
\hline 10 & 261 & BORDE? & haz & Monoc. (herbácea) & No det. & No det. & 4 \\
\hline 11 & CDF2019 & BASE O & cosido & Monoc. (herbácea) & Cyperaceae & hoja & $\mathrm{No}$ \\
\hline 11 & 261 & BORDE? & haz & Monoc. (herbácea) & No det. & No det. & tvo det. \\
\hline & CDF2019 & BASE O & cosido & Monoc. (herbácea) & Cyperaceae & hoja & \\
\hline 12 & E5A fondo cubeta & BORDE? & haz & Monoc. (herbácea) & No det. & No det. & No det. \\
\hline 13 & CDF2019 E5A & CUERDA & cordeles & Monoc. (herbácea) & No det. & No det. & - \\
\hline
\end{tabular}

Tabla 1: Características representativas del conjunto de cestería de Coves del Fem. / Characteristic features of the basketry assemblage from Coves del Fem. 


\section{MATERIALES}

El conjunto de producciones vegetales recuperado en Coves del Fem está compuesto por 53 fragmentos de pequeñas dimensiones que corresponden a restos de cestería y un elemento de cordelería. A pesar de la elevada fragmentación del conjunto se ha partido de la hipótesis que todo el conjunto de cestería procede de un único objeto, ya que todos los fragmentos recuperados provienen de la misma estructura arqueológica.

Las piezas de cestería se conservan carbonizadas en casi su totalidad, a excepción de algunas fibras. Algunas de ellas conservan restos de sedimento de un color ferruginoso, que recuerda al del óxido y también ciertas manchas de sedimento blanquecino, que podría corresponder a restos de caliza calcinada hallada en la estructura. De hecho, las fibras se encontraron en la base de la capa superior de la citada subestructura E5A donde también se documenta la aparición de un nivel de arena quemada con manchas de caliza calcinada.

Para su análisis morfotécnico, se ha optado por el estudio de aquellos fragmentos más relevantes. Así pues, se han estudiado y descrito de forma separada los 12 fragmentos de cestería que conservan un mayor rango de características representativas y el fragmento de cordelería (Tabla I, Figura 3). Estas características representativas se basan en las mayores medidas conservadas, identificación de algún tipo de parte funcional del objeto y medidas necesarias para su estudio morfotécnico.

\section{METODOLOGÍA}

El análisis técnico y morfológico de los restos de cestería llevado a cabo se fundamenta en los trabajos de Adovasio (1977) y Croes (1977). Entre las técnicas cesteras se distinguen la cestería tejida o trenzada, la cestería cordada o ligada y la cestería en espiral cosida o en espiral verdadera (Alfaro 1984). La cestería recuperada en Coves del Fem se engloba dentro de la técnica de espiral cosida, la cual está formada por una trama (elementos horizontales pasivos) y por una urdimbre (elementos verticales activos). Los haces de la trama se van acumulando en forma de espiral para crear el objeto cestero, mientras se van uniendo entre sí a través de las puntadas en forma perpendicular de la urdimbre, las cuales rodean o envuelven cada haz de la trama (Croes, 1977).

\begin{tabular}{|c|c|c|c|c|c|c|}
\hline $\begin{array}{l}\text { Ancho. máximo } \\
\text { haz }(\mathrm{mm})\end{array}$ & $\begin{array}{l}\text { Ancho mínimo } \\
\text { puntada }(\mathrm{mm})\end{array}$ & $\begin{array}{l}\text { Ancho máximo } \\
\text { puntada }(\mathrm{mm})\end{array}$ & $\begin{array}{l}\text { Número haces } \\
\text { conservados }\end{array}$ & $\begin{array}{l}\text { Longitud por An- } \\
\text { chura }(\mathrm{mm})\end{array}$ & $\begin{array}{l}\text { Espaciado } \\
\text { espiral }\end{array}$ & $\begin{array}{l}\text { Tipo y forma } \\
\text { puntada }\end{array}$ \\
\hline 19 & - & - & No det. & $45^{\star} 21$ & - & No det. \\
\hline No det. & 4 & 5 & No det. & $18 * 9$ & - & No det. \\
\hline No det. & 2 & 3 & No det. & $10 * 6$ & - & No det. \\
\hline No det. & 3 & 5 & No det. & $8 * 5$ & - & No det. \\
\hline No det. & 1 & 2 & No det. & $7 * 2$ & - & No det. \\
\hline 4 & 5 & 6 & 1 & $31 * 8$ & - & Simple entrelazada \\
\hline 9 & No se conserva & No se conserva & No det. & $27^{*} 9$ & - & No det. \\
\hline- & - & - & - & $35 * 3$ & - & - \\
\hline 19 & No det. & No det. & No det. & $47^{*} 16$ & - & No det. \\
\hline 6 & 4 & 5 & No det. & $38 * 23$ & No det. & Simple atravesada \\
\hline No det. & No det. & No det. & No det. & $39 * 24$ & No det. & No det. \\
\hline No det. & No det. & No det. & No det. & $34^{*} 27$ & No det. & No det. \\
\hline- & - & - & - & $6,6 * 1,3$ & - & - \\
\hline
\end{tabular}



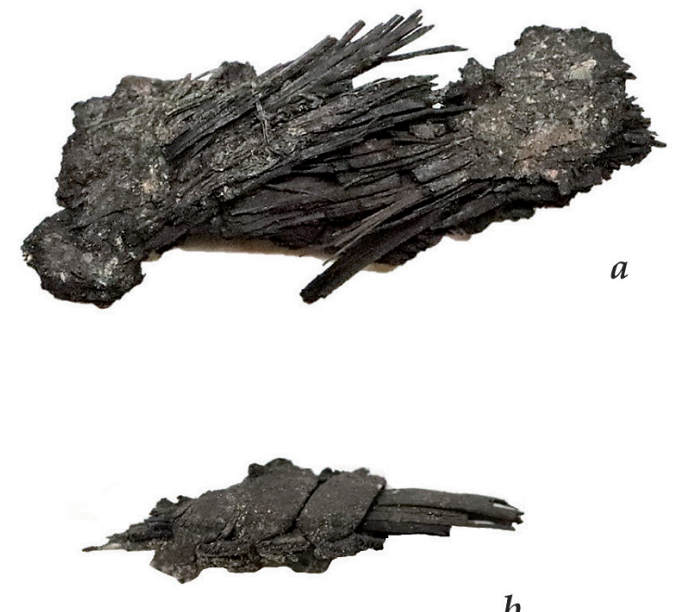

$b$
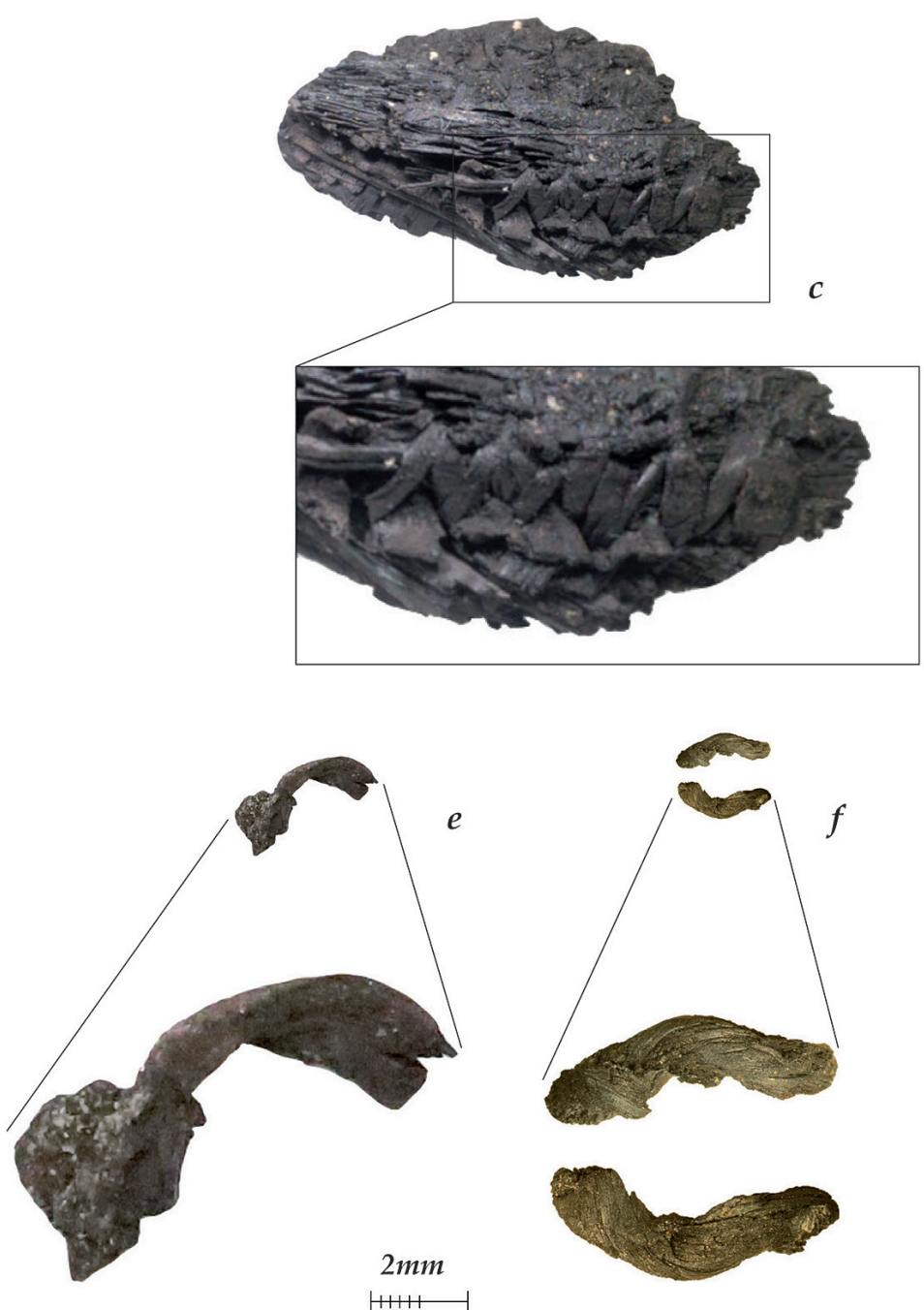
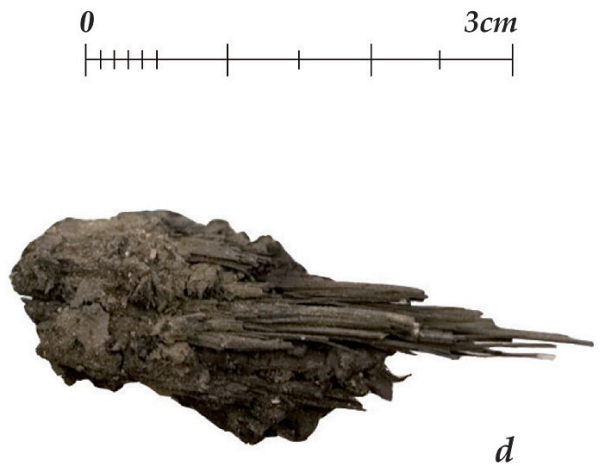

Fig.3. Fragmentos de cestería que conservan un mayor rango de caracter
greater range of representative characteristics and the cordage fragment.

Se ha medido la longitud y la anchura de cada fragmento, así como la anchura mínima y máxima tanto de los haces como del cosido (elementos pasivos y activos respectivamente), a fin de obtener datos sobre la confección y consistencia final de la pieza. Así mismo, en los casos que ha sido posible, se ha determinado el número de haces conservados y el tipo y forma de la puntada, para ello se ha seguido la propuesta de Adovasio (1977).

Según Adovasio (1977), la puntada del cosido puede ser simple, intrincada/compleja o envuelta. Las puntadas simples resultan en espirales cerradas, donde los haces adyacentes están bien unidos y sin espacio entre ellos. Las puntadas intrincadas o complejas suelen dejar espaciado entre haces, ya que en la unión de los mismos las puntadas realizan un falso nudo entre el haz nuevo y el antiguo. Finalmente, en el caso de las puntadas envueltas el haz nuevo se ve envuelto por la puntada varias veces.
Asimismo, la forma de la puntada puede ser entrelazada o unida, no entrelazada o separada y atravesada (Adovasio 1977) (Figura 4). Las puntadas entrelazadas o unidas buscan el haz superior a través de entrelazarse en diagonal con la puntada del haz anterior. Las puntadas no entrelazadas o separadas hacen lo mismo pero sin entrelazarse con la puntada del haz anterior, o sea, que no pasa a través de ninguna otra puntada. Por último, las puntadas atravesadas buscan el haz superior después de atravesar la puntada del haz anterior, esta perforación provoca un efecto de bifurcación en la puntada atravesada. Cada tipología de puntada puede perforar o rodear el haz anterior.

En el caso de la cordelería el análisis morfotécnico se basa en el trabajo de Hurley (1979) y en el de Carr y Maslowski (1995). El fragmento de cordelería se ha clasificado según sus características morfológicas y técnicas. Para caracterizar el tipo de producción se ha tenido en cuenta el número de cordeles o elementos 


\section{Puntada entrelazada o unida}



Puntada no entrelazada o separada
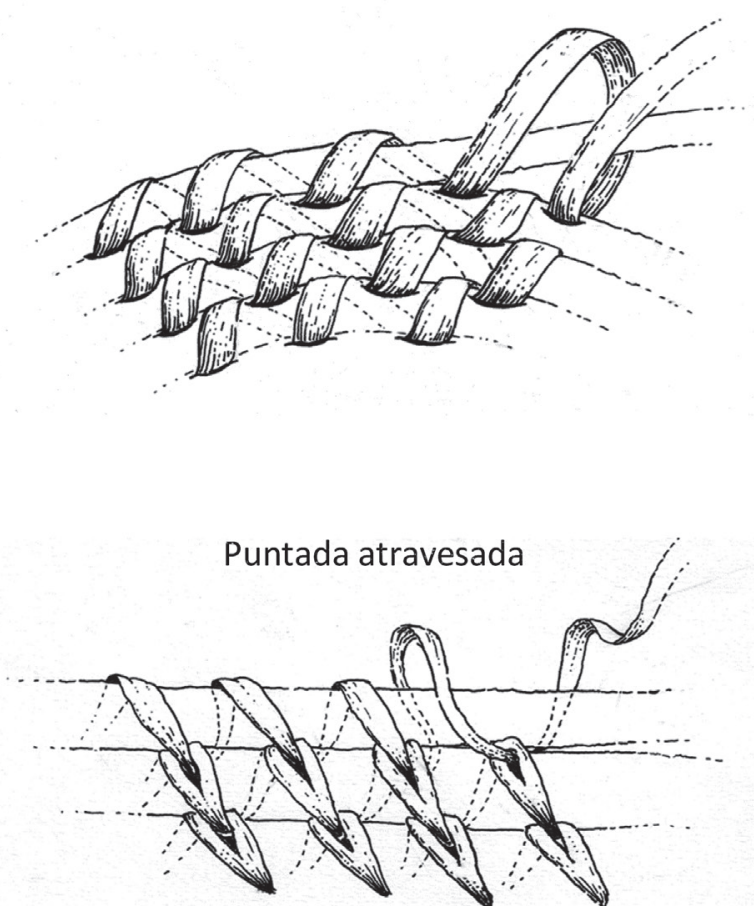

Fig.4. Forma de la puntada en cestería de espiral cosida: entrelazada o unida, no entrelazada o separada y atravesada (extraído de Romero-Brugués et al. 2021). / Sewn spiral basketry stitch shape: interlocking stithc, non-interlocking stitch and split sitch (taken from Romero-Brugués et al. 2021).

utilizados para producir la cuerda, el ángulo de torsión y la dirección de la torsión. El ángulo de torsión mide la inclinación de la torsión respecto al eje vertical de la cuerda, diferenciando entre ángulos suaves (menores de $10^{\circ}$ ), medianos (entre $10^{\circ}$ y $25^{\circ}$ ) y cerrados (entre $25^{\circ}$ y $45^{\circ}$ ). Mientras que la dirección de la torsión distingue entre cuerdas con torsión hacia la izquierda (de tipo Z) o con torsión hacia la derecha (de tipo S). Una cuerda de tipo Z tiene el segmento más largo inclinado desde la parte superior derecha hacia la parte inferior izquierda, mientras que la de tipo S presenta la inclinación de izquierda a derecha. Asimismo se registra la torsión de los cabos que componen la cuerda, Se han tomado también las medidas mínima, máxima y media de largo y ancho.
Por último, la materia prima usada para la confección de los restos de cestería y cordelería ha sido identificada mediante la observación de la estructura anatómica y la comparación con colecciones de referencia modernas y bibliografía especializada (Brinkkemper y van der Heijden, 2012; Evert, 2006; Schweingruber et al., 2011). Para la observación se ha utilizado un microscopio óptico de campo de luz oscura reflejada (BF-DF). Con el objetivo de minimizar el impacto y garantizar la integridad del objeto, la observación de los rasgos anatómicos de la cuerda se ha llevado a cabo directamente sobre la superficie y las fracturas que presentaba, sin ningún tipo de preparación de la muestra. En el caso de las fibras de cestería se aprovecharon las fracturas de los elementos de cestería.

\section{RESULTADOS. EL CONJUNTO DEL MATERIAL VEGETAL}

\subsection{Características morfotécnicas: la cestería y la cordelería}

Por lo que respecta a las dimensiones de los fragmentos de cestería conservados, éstos oscilan entre los 7 y $47 \mathrm{~mm}$, con una anchura comprendida entre los 2 y 27 mm (Tabla I, Figura 5). El espesor no se ha podido determinar en ninguno de los restos cesteros, dado que se presentan compactados con sedimentos. La alta fragmentación del conjunto no permite obtener datos del tamaño original de las piezas. Aun así, destacan cinco fragmentos por sus medidas. Por un lado, tenemos lo que podrían corresponder a dos fragmentos de haz: el registro 1 que conserva una longitud de 45 $\mathrm{mm}$ y una anchura de $21 \mathrm{~mm}$ y el registro 9 con una longitud de $47 \mathrm{~mm}$ y una anchura de $16 \mathrm{~mm}$. Por otro lado, tres fragmentos de lo que podrían ser fragmentos de borde o base: el registro 10 con una longitud de 38 $\mathrm{mm}$ y una longitud de $23 \mathrm{~mm}$, el registro 11 con una longitud de $39 \mathrm{~mm}$ y una anchura de $24 \mathrm{~mm}$ y el registro 12 con una longitud de $34 \mathrm{~mm}$ y una anchura de 27 $\mathrm{mm}$. Los registros 1, 7 y 9 presentan fibras de haz poco compactadas, aunque conservan una misma dirección. Estos tres fragmentos tienen las fibras del haz unidas por bloques sólidos de sedimento y fibras sueltas, en las partes distales o proximales de las piezas. El registro 8, el único haz conservado de forma individualizada, podría corresponder a parte de estas fibras de haces. Los registros 3, 4 y 5 representan 3 puntadas de cosido individualizadas. Cabe resaltar en el registro 4 la existencia de ciertas marcas superficiales, seguramente resultado de haber envuelto algún material. Solo el registro 6 conserva un haz que aún sigue envuelto por 3 puntadas del cosido (Figura 5).

En lo que respecta al fragmento de cuerda se trata de un pequeño elemento conservado de 6,6 mm de largo y un diámetro medio entorno a los 1,3 mm (entre 0,9 mm diámetro mínimo y 1,6 mm diámetro máximo) (Tabla 1). Se encuentra carbonizado con un buen estado de conservación. Se aprecian las líneas de división 
de las fibras de sus cordeles, así como un fragmento del posible segundo cordel de la cuerda en un extremo del objeto. No se aprecian cubrimientos o trazas

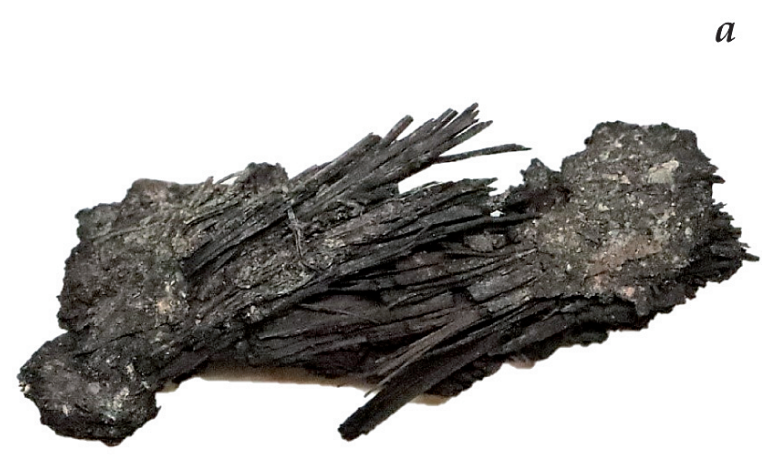

$b$

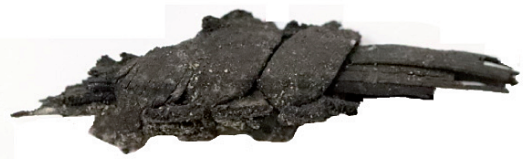

0

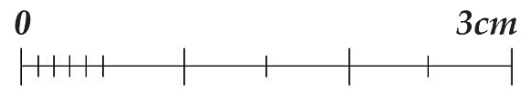

de ningún tipo, su textura superficial se aprecia lisa, sin rugosidades, y sus extremos se encuentran fragmentados (Figura 6).

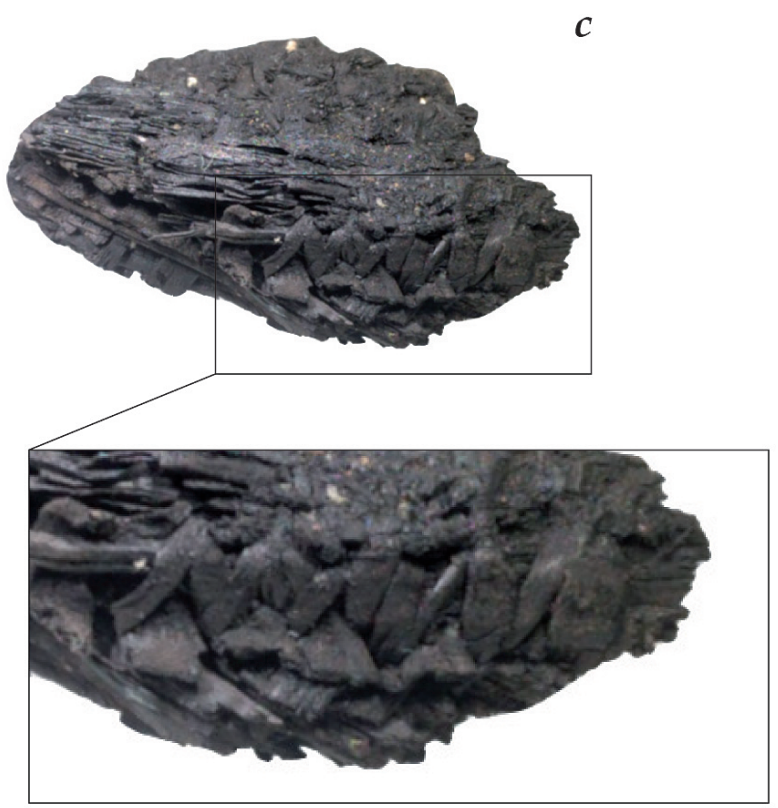

Fig.5. Fragmentos de cestería que conservan un mayor rango de características representativas. a) Fragmento de fibras del haz con una ligera torsión S (registro 1), b) detalle de puntada simple entrelazada (registro 6). c) puntada simple atravesada (registro 10). / Basketry fragment with representative features: a) Slight S-twisted bundle fibres (Reg. 1), b) Simple interlocking stitch (Reg. 6), c) Simple split stitch (Reg. 10).
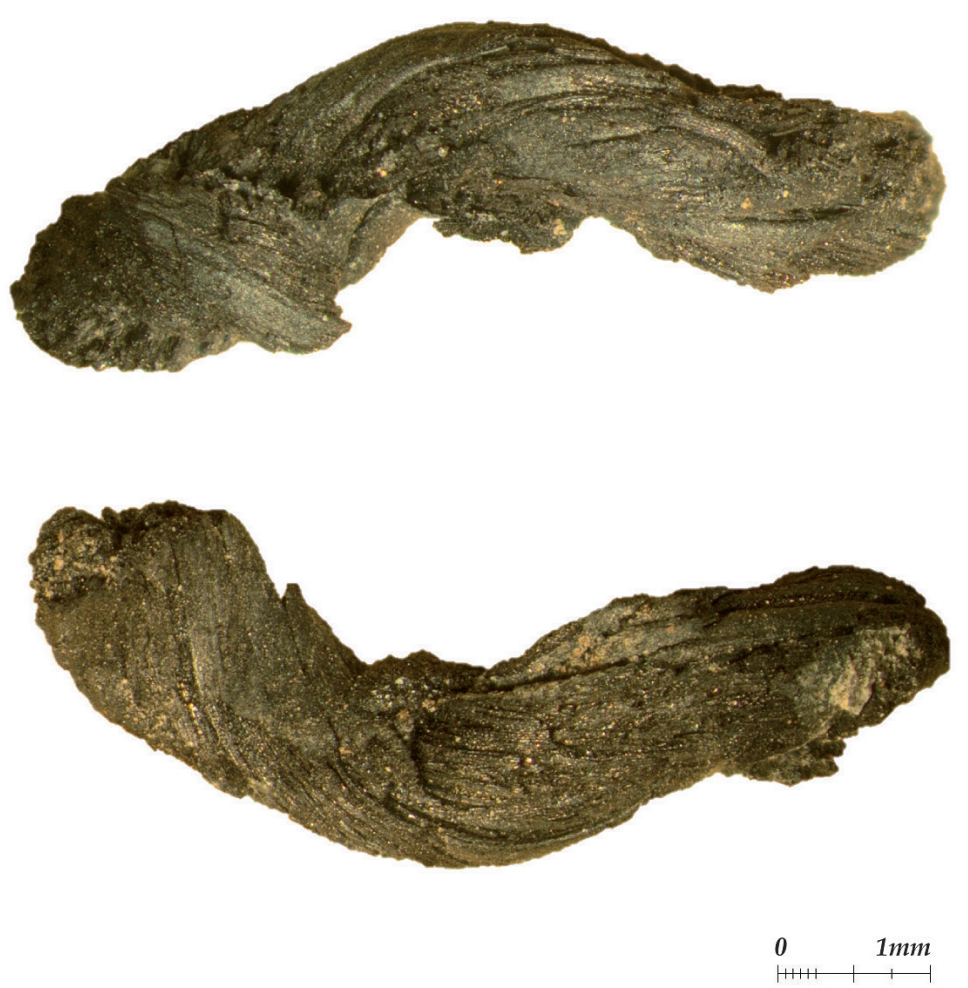

Fig.6. Vista anterior y posterior del fragmento de cuerda de Coves del Fem. / Anterior and posterior views of the cordage fragment. 


\subsection{Materia prima}

Todos los fragmentos de cestería estudiados de Coves del Fem han sido identificados como fibras de monocotiledóneas. Concretamente, las fibras del cosido han sido identificadas como ciperáceas (familia Cyperaceae), muy probablemente juncos, mientras que no ha sido posible llegar a este nivel de determinación en el caso de las fibras del haz. Además, se ha determinado la parte anatómica de la planta utilizada que en todos los casos corresponde a la parte de las hojas (Herrero-Otal et al., 2021) (Figura 7a).

A diferencia de las fibras utilizadas para la confección del cesto, en el caso del fragmento de cuerda, encontramos un posible tratamiento previo de la fibra antes de la fabricación del cordel. Éste consistiría en la división del tallo o la hoja de la planta en diversas unidades hasta conseguir fibras más delgadas y maleables. Esto se evidencia por la observación de diferentes elementos tanto en el corte transversal y en la superficie del objeto. En el primero observamos una clara distinción de fibras más pequeñas obtenidas a partir de la división física de una de mayor tamaño (Figura 7b). Además, en estos cortes observamos también los haces vasculares de morfología típica de plantas monocotiledóneas, siendo independientes los unos de los otros (Figura 7c). La división de la hoja o tallo en unidades más pequeñas dificulta la determinación de la materia primera a partir del plano transversal, ya que no se aprecia la estructura natural de la planta. Las observaciones más informativas en el caso del cordel son las que se obtienen de su superficie longitudinal. Se aprecia, por una parte, la organización celular de la epidermis de la planta, que se puede diferenciar por unidades celulares de pared sinuosa cómo las que presentan los fitolitos de epidermis de herbáceas. Además, se observan unos elementos con tipologías celulares distintas correspondientes a los estomas. Estos son válvulas que permiten el intercambio gaseoso entre el interior y el exterior de la planta a través del poro central Ilamado ostiolo. Los estomas están presentes en los tallos y en las hojas de las plantas siendo en estas últimas mucho más abundantes, sobre todo en la cara adaxial. Su disposición típica es longitudinal y se alternan a lo largo de epidermis (Figura 7d). En otras zonas de la superficie de la cuerda, observamos también los haces vasculares, ya mencionados, pero en corte longitudinal, juntamente con células de gran tamaño correspondientes al tejido parenquimático. Por lo tanto, en este caso observamos partes internas de la planta. Esto no sería posible sin la torsión a la que han estado sometidas las fibras para confeccionar la cuerda y que permite la visualización de los elementos tanto internos como externos de la hoja o tallo de la planta utilizada. En este caso, lo que se observa de los haces vasculares es el xilema que se presenta en forma de elementos largos con líneas transversales relativamente juntas en su interior, envueltas de células del parénquima vascular (Figura 7e). A pesar de haber identificado diferentes características de la materia prima utilizada para la ma-
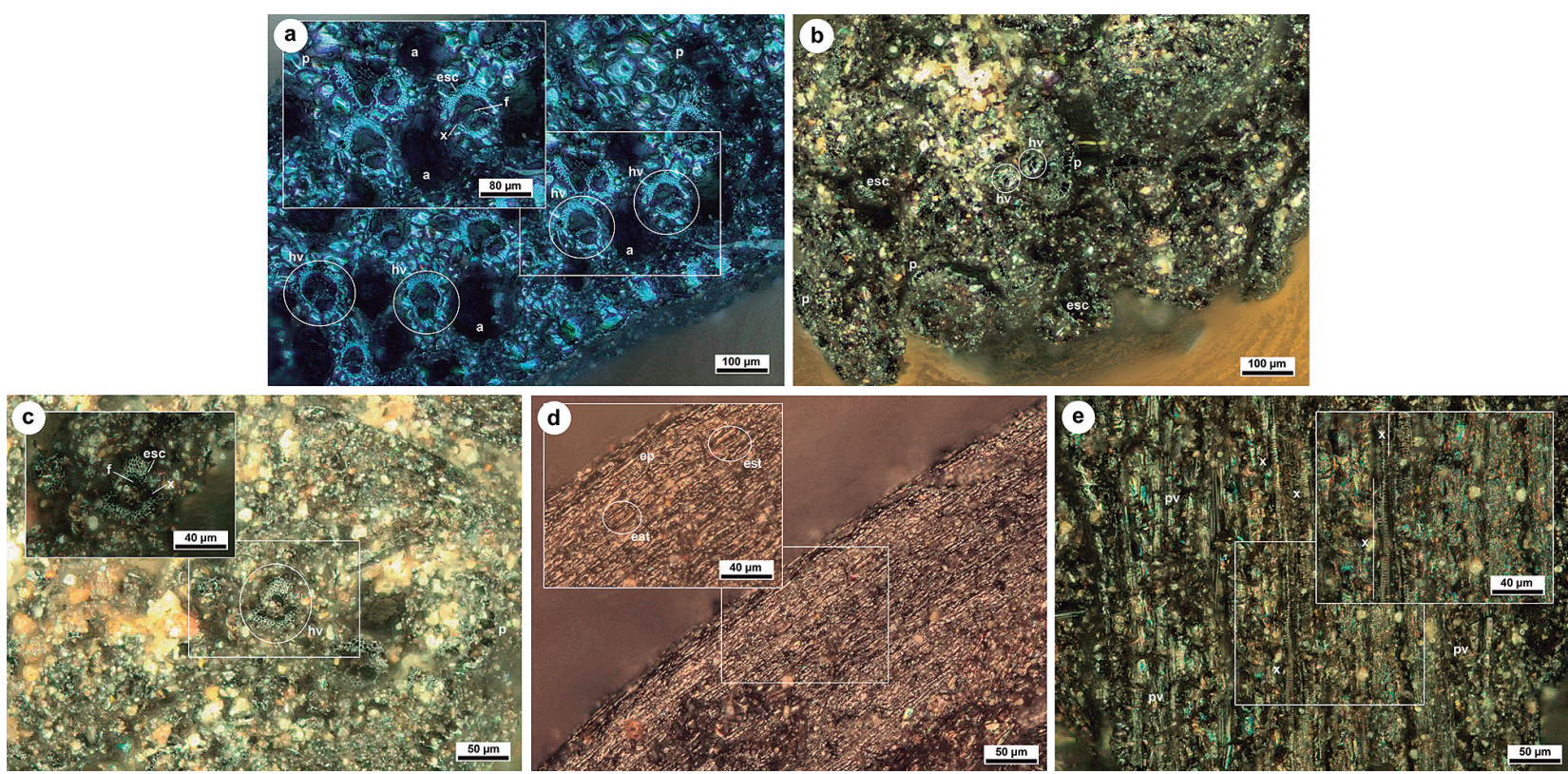

Fig.7. Imágenes de microscopia óptica de los restos vegetales de Coves del Fem (a: cestería, b-e: cordelería). a) Visión transversal de una puntada (familia Cyperaceae), b) Visión transversal general, c) Visión transversal al detalle de los haces vasculares de monocotiledóneas, d) Visión longitudinal de la epidermis y los estomas, e) Visión longitudinal de los haces vasculares (xilema) y parénquima asociado. (a: aerénquima, ep: epidermis, esc: esclerénquima, est: estomas, f: floema, hv: haces vasculares, p: parénquima, pv: parénquima vascular, $x$ : xilema). / Optical microscopy images of vegetal remains from Coves del Fem (a: basketry, b-e: cordage): a) Cross-section view of a stitch (Cyperaceae family), b) General cross-section view, c) Detailed cross-section view where monocots vascular bundles are observed, d) Longitudinal view of the epidermis and stomata, e) Longitudinal view of vascular bundles (xylem) and vascular parenchyma. (a: aerenchyma, ep: epidermis, esc: sclerenchyma, est: stomata, f: phloem, hv: vascular bundles, p: parenchyma, pv: vascular parenchyma, x: xylem). 
nufacturación de la cuerda, no se observan elementos determinantes a nivel de familia, más allá de pertenecer al grupo de las monocotiledóneas.

\subsection{Técnica y categorías morfotécnicas}

El tipo de técnica empleada en la cestería de Coves del Fem es la técnica de espiral cosida. Las características técnicas documentadas se presentan en la Tabla I. En particular, cabe destacar las fibras del haz del registro 1, las cuales presentan una ligera torsión S (izquierda), que podría corresponder a la torsión que reciben los haces en la cestería de paja o de espiral cosida en el proceso de elaboración (Figura 5). El grueso de los haces y de las puntadas del cosido muestran medidas variadas; con respecto a los haces, éstos están comprendidas entre los $3-4 \mathrm{~mm}$ y $19 \mathrm{~mm}$; $\mathrm{y}$, en cuanto las puntadas del cosido, entre los $1-2 \mathrm{~mm}$ y 5 - $6 \mathrm{~mm}$. Cabe mencionar que los haces no conservan su forma original por haber sufrido deformaciones post-deposicionales y, por este motivo, sus medidas son estimativas. Se ha podido determinar la tipología de las puntadas del cosido en 2 registros. Todas corresponden a puntadas simples con 2 variantes en cuanto a forma de la puntada: puntada simple entrelazada (simple interlocking) en el registro 6 (3 puntadas) y puntada simple atravesada (simple split) en el registro 10 (5 puntadas) (Figura 5). No ha sido posible determinar la curvatura horizontal ni la curvatura vertical, así como tampoco el espaciado de la espiral de las piezas. Por lo que respecta a las categorías morfotécnicas se han conservado fragmentos de haz (5 de 12, el 41,7\%), fragmentos de puntada de cosido (3 de 12, el 25\%), fragmentos de base o borde ( 3 de 12 , el $25 \%$ ) y un fragmento de resto informe (1 de 12, el 8,3\%)

En lo que respecta al fragmento de cuerda se trata de una cuerda confeccionada mediante la técnica de la torsión, con una dirección de torsión tipo Z. La cuerda solo conserva uno de sus cabos que presenta una torsión inicial en s y una hipotética torsión final en Z, el resultado sería una cuerda de tipo Zs,s con dos cabos. Su ángulo de torsión oscila entre los $20^{\circ}$ y los $25^{\circ}$, por lo que se encuentra dentro de los ángulos medios.

\section{DISCUSIÓN}

\subsection{Materia prima en su contexto vegetal}

Entre los restos de cestería y cordelería de Coves del Fem se ha identificado exclusivamente el uso de monocotiledóneas. La clase de las monocotiledóneas se compone de numerosas especies de amplia distribución, entre las que destacan diversas especies herbáceas. Muchas de ellas presentan tallos flexibles, propiedades muy adecuadas para la cestería y la cordelería. En el caso de la cestería tanto los haces como las puntadas se manufacturaron con este tipo de fibras, si bien se pudo precisar que pertenecían a la familia de las ciperáceas (Cyperaceae), probablemente jun- cos. Estos resultados indican que entre las especies vegetales al alcance se seleccionaron un determinado tipo de plantas para la elaboración de estos productos. Además, se pudo determinar con una preferencia por la elección de hojas (Herrero-Otal et al., 2021)

Como se ha señalado, el registro antracológico y palinológico de Coves del Fem indica que durante la fase epicardial, a la que corresponden los restos de cestería y cordelería, el paisaje estaría dominado por pinares de pino tipo albar (Pinus sp. tipo sylvestris-nigra) bosques mixtos de Quercus sp. caducifolio y Quercus sp. tipo ilex-coccifera, y especies higrófilas que crecerían en los ambientes de ribera. El registro polínico ha revelado además la presencia de ciperàcies y otras monocotiledóneas en el entorno de Coves del Fem (Palomo et al., 2018). Las ciperàcies, al igual que otras familias de monocotiledóneas, crecen en ambientes húmedos y por tanto habrían encontrado un habitat favorable en las inmediaciones del río Montsant, donde se localiza el yacimiento. Los datos arqueobotánicos corroboran, por lo tanto, la disponibilidad de esta familia en el entorno. Esto permite plantear que la materia prima para la confección de objetos cotidianos de fibras vegetales como cestería y cordelería se pudo obtenir a nivel local.

De acuerdo a la investigación etnográfica, plantas herbáceas como el junco, las juncias o la enea son plantas muy aptas para hacer esteras, cubiertas, cordelería o cestería. Aunque en la actualidad se conoce poca cestería hecha de herbáceas, históricamente sí se documenta la cestería hecha de juncos, probablemente trabajados en espiral (Kuoni, 1981).

El uso de monocotiledóneas está bien documentado en otros contextos arqueológicos, así como en algunas de las primeras evidencias textiles y de cestería provenientes de la cuenca mediterránea oriental y del Oriente Próximo. Este es el caso de los restos vegetales encontrados en Jericó (Crowfoot, 1982), Nahal Hemar (Schick, 1988) o Tell Halula (Alfaro, 2012). También los cestos documentados en la península ibérica fueron elaborados principalmente con fibras de monocotiledóneas (Herrero-Otal et al., 2021). Las fibras monocotiledóneas están presentes entre la cestería de La Draga, tanto para los haces como las puntadas, aunque también se usaron fibras de líber de tilo (Tilia sp.) para las puntadas y varitas de avellano como haces (Romero-Brugués et al., 2021).

Juntamente con La Draga, Coves del Fem constituye el único caso en el que el material vegetal escogido es totalmente diferente al identificado en otros yacimientos neolíticos de la península ibérica. Las diferencias en el uso de las materia primas vegetales en el neolítico peninsular sin duda están relacionados con la disponibilidad de la materia prima. El material vegetal que se documenta mayormente en el sur y levante peninsular es el esparto, siendo el ejemplo más ilustrativo la cestería de Cueva de los Murciélagos. El esparto 
actualmente tiene su área de distribución natural en las zonas más áridas del sur y el este peninsular, en cambio no se documenta en el Nordeste de la Península, donde no se dan condiciones ambientales favorables para su crecimiento. Durante el Neolítico los registros arqueobotánicos de Coves del Fem y La Draga (Piqué et al., 2021) indican que el clima era más húmedas que en la actualidad, lo que sugiere que el esparto no habría encontrado en el nordeste peninsular las condiciones adecuadas para su crecimiento. En cambio, tanto Coves del Fem como la Draga se localizan en ambientes húmedos, ya sea por su proximidad a cursos de agua, en el caso de Coves del Fem, o del lago de Banyoles en el caso de la Draga, lo que habría favorecido el crecimiento de plantas como las ciperáceas que tiene su hábitat en estos ambientes húmedos. Estas monocotiledóneas son actualmente abundantes en las inmediaciones de estos yacimientos, donde están representadas por diversas familias botánicas.

La elección de la materia prima y la selección de las partes más propicias para cestería en Coves del Fem es el resultado de un alto conocimiento de los recursos vegetales del entorno, sus propiedades y manejo de las mismas para la manufacturación de objetos. En otros yacimientos del Neolítico antiguo, como el asentamiento de La Draga (Banyoles), se han identificado herramientas relacionadas con el procesado de fibras vegetales a través del análisis funcional practicado sobre instrumentos de diversa naturaleza, como láminas de sílex (Gibaja, 2011), conchas marinas (Clemente y Cuenca, 2011) y punzones de hueso (De Diego et al., 2018). En este sentido, en Coves del Fem se han recuperado punzones de hueso que podrían haber sido utilizados para el trabajo de materias vegetales, entre otras funciones, aunque su análisis se halla todavía en curso.

\subsection{La cestería y la cordelería de Coves del Fem en el contexto de las producciones en base a fibras vegetales neolíticas: cronología, técnica de producción y funcionalidad}

Como ya se ha mencionado, los restos vegetales raramente se conservan en el registro arqueológico, por lo que tenemos un conocimiento limitado de las tecnologías perecederas, tanto en los que se refiere a los procesos de producción como de los usos a los que se destinaron entre las sociedades prehistóricas (Hurcombe 2014). Las escasas evidencias de cestería y cordelería recuperadas en contextos arqueológicos permiten indagar en la gestión y aprovechamiento de fibras vegetales para la elaboración de objetos y contribuir a conocer mejor el rol que estos tuvieron. En este sentido, los hallazgos de Coves del Fem contribuyen al conocimiento de las técnicas de cestería y cordelería neolítica de la península ibérica y aportan datos sobre su posible función.

A nivel cronológico, el nivel donde se han localizado los restos de cestería y cordelería se sitúa en la pri- mera mitad del V milenio en cronología calibrada BC y, por lo tanto, se trata de unos de los materiales cesteros más antiguos de la península ibérica. Las características morfotécnicas y la identificación de las materias primas sugieren que todo el conjunto de cestería correspondería a una sola pieza. Todos los fragmentos provienen de la misma subestructura arqueológica E5A y el grosor de los haces y de las puntadas del cosido son similares. Así mismo, todos los restos analizados han sido determinados como fibras de monocotiledóneas y, concretamente, las fibras del cosido como hojas de Cyperaceae. Los restos corresponden a fragmentos de haz que conformarían la espiral, diversas puntadas sueltas y algunos fragmentos mejor conservados que corresponderían a parte del borde o de la base de la misma pieza de cestería. El estado de carbonización, fragmentación y tamaño de los restos no permite vislumbrar la forma original de la pieza ni el tamaño de la misma, pero el hecho de que todos los fragmentos estaban asociados permiten plantear que probablemente proceden de un único objeto.

En lo que respecta a la técnica de producción, se ha podido determinar que el objeto fue elaborado mediante la técnica de espiral cosida. Esta técnica cestera es una de las más arcaicas de nuestro pasado (Kuoni, 1981). Con este procedimiento es posible elaborar objetos planos o con volumen con multitud de utilidades y formas a partir de un punto central, donde se cosen haces de fibras entre sí a través de una espiral. Por ejemplo, es conocida la técnica en espiral cosida en yacimientos del Próximo Oriente, como Nahal Hemar (8200 - 7300 cal BC) (Shick, 1988) o Kefar Samir en Israel (5517 - 5038 cal. BC) (Galili y Schick, 1990), Çatal Hüyük en Turquía (7400 - 6200 cal. BC) (Mellaart, 1967, Wendrich y Ryan, 2012) o El Fayum y Badari en Egipto (4000 cal. BC) (Lucas, 1948). En el noreste de la península ibérica, en el yacimiento lacustre de La Draga (Banyoles), los 8 cestos individualizados se adscriben a la técnica en espiral cosida y se han distinguido diferentes usos según el tipo de puntadas para la confección de la espiral, entre ellos el transporte y el almacenaje de alimentos (Romero-Brugués et al., 2021). En la Cueva de los Murciélagos de Albuñol (Granada), en el sur peninsular y en un contexto funerario, también se documentan las técnicas de cestería en espiral cosida, así como la tejida y la trenzada. En este caso se han documentado numerosos objetos producidos con técnicas cesteras, determinados como parte de los objetos funerarios y de uso cotidiano del Neolítico antiguo (Cacho et al., 1996).

Por lo que respecta a la funcionalidad de los restos de cestería de Coves del Fem, la técnica documentada como cestería en espiral cosida permite elaborar multitud de formas, con amplias funcionalidades, ya que la técnica es suficientemente versátil para producir objetos tanto planos, como con volumen. No obstante, se propone un posible uso relacionado con el almacenaje subterráneo de alimentos. Esta hipótesis surge 
del contexto de procedencia de los restos y de las características técnicas documentadas. Los fragmentos se recuperaron en la base de la primera capa de una pequeña fosa que se interpretó como una estructura de almacenamiento, dónde los restos del cesto podían haber formado parte de un posible revestimiento de la misma. Sin embargo, debido al estado de fragmentación del objeto, no se puede descartar que los restos representen el cesto de almacenaje mismo. Es decir, los restos de cestería pueden no indicar el revestimiento, sino la estructura de almacenamiento real colocada en el interior de la fosa.

El tipo de puntadas documentadas en el cosido de los restos de cestería son no entrelazadas y atravesadas. Este tipo de cosido permite confeccionar trabajos prietos y construir objetos compactos, densos y pesados. Estas características se relacionan con recipientes inmóviles destinados al almacenamiento, lo que parece reforzar la hipótesis de que el objeto de cestería estaría relacionado con el almacenaje.

La funcionalidad de almacenamiento de los restos cesteros se atribuye por lo tanto a las características morfotécnicas y su ubicación en el interior de una fosa. El objeto cestero habría servido bien como protección de las paredes de la estructura o bien como dispositivo de almacenamiento en sí mismo, sin que sea posible poder precisar más debido al estado de fragmentación. Cabe señalar que en la citada fosa, junto a los restos de cestería, se recuperaron semillas de cereal carbonizadas, así como restos cerámicos y fragmentos de tallos vegetales carbonizados, lo que hace pensar que podría haber servido como lugar de almacenamiento en sus orígenes, acción continuada en el tiempo hasta su desuso final.

La identificación de instalaciones de almacenaje prehistóricas, como pueden ser los silos revestidos con cestería, proveen de pruebas indirectas de estructuración del espacio, en el sentido de organización y gestión de la extensión habitacional. En el caso de Coves del Fem cabe señalar que la reducida superficie excavada hasta la fecha no permite todavía definir como se organizó el espacio durante la fase epicardial. La reiteración de estructuras subterráneas relacionadas con el almacenaje en esta fase permite platear un uso reiterado del espacio para esta finalidad. Se han documentado diversas estructuras de almacenaje, una de ella de grandes dimensiones y otras, como la que presentamos en este trabajo, de pequeño tamaño. Estas estructuras difieren en su uso temporal y en base a sus dimensiones muy posiblemente en el material almacenado. Las paredes de las estructuras, excavadas en estratos compuestos de limos finos poco consistentes, podrían haberse visto reforzadas por los elementos de cestería.

El uso de elementos de cestería para revestimiento de paredes de estructuras de almacenamiento es una funcionalidad que está bien documentada en el registro arqueológico. A modo de ejemplo podemos citar las fosas de almacenamiento bien conservadas con forro de cestería de espiral cosida (coiled basketry), datados entorno 4295 - 4467 cal BC, del yacimiento de El Fayum (Egipto) (Wendrich y Holdaway, 2017). Por otra parte, en la prehistoria europea, también se conocen varios ejemplos similares. Por ejemplo, en el yacimiento de Gearraidh na h'Aibhne, en la isla de Lewis (Escocia), se han determinado restos de ramas de avellano retorcidas que forraban un silo ovalado y que se interpretaron como una estructura cestera de mimbre de la Edad del Bronce (2815 - 2780 cal BP) (Duffy, 2006). Asimismo, en el poblado del Bronce Final de Lavra (Portugal), se documentaron silos con ramas carbonizadas entrecruzadas que parecían elementos de protección de paredes forradas (Sanches, 1987).

Así mismo se han documentados silos forrados con cestería o estructura vegetal a partir de hallazgos indirectos. En el yacimiento de Gussage All Saints (Salisbury, Inglaterra) se han descubierto huecos en las paredes de algunos silos que podrían formar parte de un recubrimiento de cestería, datados en la Edad del Hierro, entorno al 500 - 450 BC (Wainwright, 1973).

Etnográficamente, el revestimiento de cestería en los silos para conseguir un mejor aislamiento se ha descrito en diversas comunidades. Por ejemplo, los silos borno y belaá ngawuli del norte de Nigeria, o en Madagascar, en Sudáfrica o Suazilandia donde se usan esteras de tejidos vegetales para las paredes (Miret, 2009).

En el pasado, seguramente esta utilidad habría sido una práctica habitual, tal y como se documenta arqueológicamente y etnográficamente. Sin embargo, en la península ibérica solo se conoce este uso de forma arqueológica a través de los restos de cestería de Cova de les Cendres, datado en $4510 \pm 40$ cal. BC., donde se documentó el revestimiento de un silo con esparto trenzado, que tendría la función de reforzar su estructura (Bernabeu-Aubán y Fumanal-García, 2009). Es importante destacar, no obstante, que la técnica utilizada difiere; mientras que en la Cova de les Cendres se usó la cestería trenzada, en Coves del Fem la técnica determinada es la espiral cosida y, por lo tanto, el hallazgo que aquí se presenta es único a nivel peninsular. Cabe mencionar como otro gran ejemplo del uso de la cestería para la conservación de alimentos el ya mencionado yacimiento de La Draga. Aunque el almacenamiento de alimentos no es subterráneo, se interpreta que los 8 cestos individualizados tendrían como una de sus funciones el almacenar alimentos aislándolos de la humedad ambiental.

El pequeño tamaño del fragmento de cuerda no permite extraer conclusiones sobre su función, tan solo describir el objeto como una cuerda de pequeño diámetro y con un ángulo de torsión mediano. Por lo tanto, se trataría de una cuerda fina y resistente. Este tipo de cuerdas son usadas por ejemplo para el almacenaje o para la fabricación de trampas, así como para urdimbres o tramas en ciertos tipos de cestería trenzada (An- 
drews, Adovasio y Carlisle, 1986). Sin embargo, el hecho de que se encontró asociado a la concentración de semillas y a los fragmentos de cestería hace plantear que podrían estar relacionados, pero no se tienen más datos para determinar la función de la cuerda.

\section{CONCLUSIONES}

En el presente estudio se ha expuesto un ejemplo singular de cestería en espiral cosida y cordelería provenientes de un contexto neolítico del noreste peninsular. Los restos de cestería recuperados en el interior de una fosa excavada en sedimentos muy poco compactados podrían haber formado parte de un mismo elemento utilizado como recipiente y armazón de las paredes y la base. El hecho de haber documentado varios tipos de puntadas (no entrelazadas y atravesadas) se puede relacionar con la función de conservación y/o almacenamiento de alimentos. En el caso del cordel recuperado, se trata de un pequeño fragmento de cuerda torsionada hecha con fibras previamente manipuladas sin que se pueda establecer una función en concreto.

La funcionalidad relacionada con la conservación y/o almacenaje de alimentos, así como su contexto en una cavidad aportan nuevos datos al conocimiento de la manufactura cestera del Neolítico, la cual se encuentra bien representada en Europa y Próximo Oriente. Así mismo, la cestería de Coves del Fem, juntamente con el conjunto recuperado en el yacimiento de La Draga, se desmarca del resto de cestería ibérica por el material vegetal escogido, ya que se utilizaron ciperáceas y/u otras herbáceas para su elaboración. Es notable remarcar también la selección de las partes del material vegetal para la manufactura cestera, como son las hojas, por lo cual se desprende que la comunidad de Coves del Fem tenía un alto conocimiento del entorno más inmediato, así como de las técnicas para la elaboración de cestos.

\section{AGRADECIMIENTOS}

Este trabajo fue apoyado por el Ministerio de Ciencia, Innovación y Universidades, España (números de subvención PID2019-109254GB-C21, PID2019109254GB-C22 y PCl2020-111992). La excavación arqueológica de Coves del Fem fue financiada por el Departament de Cultura (Generalitat de Catalunya) CLT009 / 18/00026. Los autores forman parte del grupo de investigación apoyado por AGAUR-Generalitat de Catalunya: TEDAS 2017 SGR 243 y ASD 2017 SGR 995. Raquel Piqué también agradece el apoyo de la Institución Catalana de Investigación y Estudios Avanzados (ICREA, Generalitat de Catalunya, España), a través del Programa Academia ICREA.

\section{BIBLIOGRAFÍA}

Adovasio, J.M., 1977. Basketry Technology: a guide to identification and analysis. Aldine Publishing Company, Chicago.
Agustí, B., Alcalde, G., Burjachs, F., Buxó, R., Juan-Muns, N., Oller, J., Ros, M.T., Rueda, J.M., Toledo, A., 1987. Dinàmica de l'ocupació de la Cova 120 per l'home en els darrers 6.000 anys. Museu d'Arqueologia, Girona.

Alcolea, M., Revelles, J., Berihuete, M., Piqué, R., Dufraisse, A., Terradas, X., Palomo, A., Bogdanovic, I., Rosillo, R., 2019. Forest resource management during Mesolithic-Neolithic transition: archaeobotanical studies in Coves del Fem site (NE Iberia). 1st Conference on the Early Neolithic of Europe: 78-79. CSIC - Institución Milá y Fontanals (IMF).

Alfaro Giner, C., 1984. Tejido y cestería en la península ibérica. Historia de su técnica e industrias desde la prehistoria hasta la romanización. Consejo Superior de Investigaciones Científicas (CSIC). Instituto español de prehistoria, Madrid.

Alfaro, C., 2012. Textiles from the Pre-pottery Neolithic site of Tell Halula (Euprhates Valley, Syria). Paléorient 38 (1-2), 41-54.

Andrews, R. L., Adovasio, J. M., Carlisle, R. C., 1986. Cordage. In: Perishable industries from dirty shame Rockshelter. Ethnology monographs 9 \& University of Oregon Antrhopological Papers 34, 51-91.

Aura-Tortosa, J., Pérez-Jordà, G., Carrión-Marco, Y., Seguí-Seguí, J.R., Jordá-Pardo, J.F. Miret-Estruch, C., Verdasco-Cebrián, C.C., 2019. Cordage, basketry and containers at the Pleistocene-Holocene boundary in southwest Europe. Evidence from Coves de Santa Maira (Valencian region, Spain). Vegetation History and Archaeobotany, 1-14. https://doi. org/10.1007/s00334-019-00758-X

Bernabeu-Aubán, J., Fumanal-García, M. P., 2009. La excavación, estratigrafía y dataciones C14. In: Bernabeu-Aubán, J., Molina-Balaguer, L. (Eds.), La Cova de les Cendres (Moraira-Teulada, Alicante), 31-52. MARQ, Diputació d'Alacant, Alacant.

Bogdanovic, I., Palomo, A., Piqué, R., Rosillo, R., Terradas, X., 2017. Los últimos cazadores-recolectores en el NE de la península ibérica: evidencias de ocupaciones humanas durante el VI milenio cal BC. In: Barceló, J.A., Bogdanovic, I., Morell B. (Eds.), Actas del Congreso de Cronometrías Para la Historia de la península ibérica (IberCrono 2017) Barcelona, Spain, September 17-19, 2016, 35-45. CEUR-WS, Barcelona.

Bosch, A., Chinchilla, J., Tarrús, J., 2000. El poblat lacustre neolític de La Draga: excavacions de 1990 a 1998. Museu d'Arqueologia de Catalunya, CASC, Girona.

Brinkkemper, O., Van der Heijden, E., 2012 Appendix A: fibre identification criteria. In: Wendrich, W. (Ed), The world according to basketry. An ethno-archaeological interpretation of basketry production in Egypt, 429-440. Leiden University, Cotsen Institute of Archaeology Press, Los Angeles.

Cacho, C., Papi, C., Sánchez-Barriga, A., Alonso, F., 1996. La cestería decorada de la Cueva de Los Murciélagos (Albuñol, Granada). Complutum extra 6(1), 105-122.

Carr, C., Maslowski, R. F., 1995. Cordage and fabrics: relating form, technology and social processes. In: Carr, C. Neitzel, J. E. (Eds.), Style, society and person, Archaeological and Ethnological perspectives, 297-343. Plenum Press, New York.

Clemente, I., Cuenca, D., 2011. Instrumentos de trabajo de concha. In: Bosch, A., Chinchilla, J., Tarrús, J. (Eds.), El poblat lacustre del Neolític antic de La Draga. Excavacions 2000-2005, 137-145. Museu d'Arqueologia de Catalunya, CASC, Girona.

Croes, D. R., 1977. Basketry from the Ozette village archaeological site: a technological, functional and comparative study. 
Washington Archaeological Research Center, Washington State University, Pullman, Washington.

Crowfoot, E., 1982. Textiles, matting and basketry.I In: Kenyon, K. M., Hoiland, T. A. (Eds.), Excavations at Jericho 4, 546-550. British School of Archaeology in Jerusalem, Oxford.

De Diego, M., Palomo, A., Piqué, R., Saña, M., Terradas, X., Clemente, I., Mozota, M., 2018. Fibre production and incipient textile technology in the Early Neolithic site of La Draga (Northeastern Spain, Banyoles - Catalonia; 5300-4900 BC. In: Bravermanová, M., Březinová, H., Malcolm-Davies, J. (Eds.), Archaelological Textiles - Links between past and present, 293-302. Technical University of Liberec, Praga.

Duffy, P. R. J., 2006. Excavation of a Bronze Age wicker container, Gearraidh na h'Aibhne, Isle of Lewis. Scottish Archaeological Internet Report, 19.

Evert, R.F., 2006. Esau's plant anatomy: meristems, cells and tissues of the plant body: their structure, function, and development. Wiley, Hoboken.

Fugazzola, M.A., 1998. La vita quotidiana del neolítico. II sitio della Marmotta sul lago di Bracciano. In: Pesina, A., Muscio, G. (Coords.), Settemila anni fa. II primo pane. Ambienti e culture delle società neolitiche, 185-192. Museo Fliulano di Storia Narurale, Comune di Udine.

Galili, E., Schick, T., 1990. Basketry and a wooden bowl from the Pottery Neolithic submerged site of Kefar Samir. Mitekufat Haeven: Journal of the Israel Prehistoric Society 23, 142-151.

Gibaja, J. F., 2011. La función de los instrumentos líticos tallados. In: Bosch, A., Chinchilla, J., Tarrús, J. (Eds.), El poblat lacustre del Neolític antic de La Draga. Excavacions 2000-2005, 91-100. Museu d'Arqueologia de Catalunya, CASC, Girona.

Herrero-Otal, M., Romero-Brugués, S., Piqué, R., 2021. Plants used in basketry production during the Early Neolithic in the north-eastern Iberian Peninsula. Vegetation History and Archaeobotany. https://doi.org/10.1007/s00334-021-00826-1

Hurley W. M., 1979. Prehistoric cordage: Identification of impressions of pottery. Taraxacum, Toronto.

Hurcombe, L.M., 2014. Perishable Material Culture in Prehistory. Investigating the Missing Majority. Routledge, Londres.

Körber-Grohne, U., Feldtkeller, A., 1998. Pflanzliche Rohmaterialien und Herstellungstechniken der Gewebe, Netze, Geflechte sowie anderer Produkte aus den neolithischen Siedlungen Hornstaad, Wangen, Allensbach und Sipplingen am Bodensee. In: Siedlungsarchäologie im Alpenvorland V. Forschungen und Berichte zur Vor- $u$. Frühgeschichte in Baden-Württemberg, Band 68, 131-242.

Kuoni, B., 1981. Cestería tradicional ibérica. Ediciones del Serbal, Barcelona.

Lucas, A., 1948. Ancient Egyptian Materials and Industries, third ed. Edward Arnold, University of California.

Maier, U., 1999. Agricultural activities and land use in a Neolithic village around 3900 BC: Hornstaad Hörnle I A, Lake Constance, Germany. Vegetation History and Archaeobotany 8, 87-94.

Médard, F., 2003. Vestiges textiles et activités de filage sur le site néolithique d'Arbon-Bleiche 3 (TG Suisse). Bulletin de la Société préhistorique française 100 (2), 375-391.

Mellaart, J., 1967. Çatal Huyuk: A Neolithic Town in Anatolia. McGraw Hill (Ed.), New York.
Miret, J., 2009. Sistemes tradicionals de conservació dels aliments en fosses i sitges. Un enfocament multidisciplinar. Documento accesible en www.scribd.com

Palomo, A., Terradas, X., Piqué, R., Rosillo, R., Bogdanovic, I., Bosch, A., Saña, M., Alcolea, M., Berihuete, M., Revelles, J. 2018. Les Coves del Fem (Ulldemolins, Catalunya). Servei d'Arqueologia i Paleontologia - Tribuna d'Arqueologia 20152016, 88-103.

Peña-Chocarro, Guillem-Pérez, L., Morales-Mateos, J., Zapata, L., 2015. Storage in traditional farming communities of the western Mediterranean: Ethnographic, historical and archaeological data. Environmental Archaeology 20(4), 379-389.

Piqué, R., Alcolea, M., Antolín, F., Berihuete-Azorín, M., Berrocal, A., Rodríguez-Antón, D., Herrero-Otal, M., López-Bultó, O., Obea, L., Revelles, J., 2021. Mid-Holocene Palaeoenvironment, Plant Resources and Human Interaction in Northeast Iberia: An Archaeobotanical Approach. Applied Sciences 11, 5056.

Romero-Brugués, S., Piqué, R., Herrero-Otal, M., 2021. The basketry at the early Neolithic site of La Draga (Banyoles, Spain). Journal of Archaeological Science: Reports, Volume 35. https://doi.org/10.1016/j.jasrep.2020.102692

Sanches, M. J., 1987. O Buraco da Pala. Um abrigo pré-histórico no concelho de Mirandela (noticia preliminar das excavaçôes de 1987). Arqueologia 16, 58-77.

Schick, T., 1988. Nahal Hemar Cave, cordage, basketry and fabrics. Atiqot 18, 31-43.

Schweingruber, F.H., Börner, A., Schulze, E. D., 2011. Atlas of stem anatomy in herbs, shrubs and trees. Springer, Berlin.

Wainwright, G. J., Spratling, M., 1973. The Iron Age settlement of Gussage All Saints. Antiquity 47, 109-130.

Wendrich W., Ryan P., 2012. Phytoliths and Basketry Materials at Çatalhöyük (Turkey): Timelines of growth harvest and objects life histories. Paléorient 38(1-2), 55-63.

Wendrich, W., Holdaway, S., 2017. Basket use, raw materials and arguments on early and Middle Holocene mobility in the Fayum, Egypt. Quaternary International 30, 1-10. 